\title{
The effect of empagliflozin on arterial stiffness and heart rate variability in subjects with uncomplicated type 1 diabetes mellitus
}

David Zl Cherney ${ }^{1 *}$, Bruce A Perkins ${ }^{2}$, Nima Soleymanlou ${ }^{3}$, Ronnie Har ${ }^{1}$, Nora Fagan ${ }^{4}$, Odd Erik Johansen ${ }^{5}$, Hans-Juergen Woerle ${ }^{5}$, Maximilian von Eynatten ${ }^{4}$ and Uli C Broedl ${ }^{5}$

\begin{abstract}
Background: Individuals with type 1 diabetes mellitus are at high risk for the development of hypertension, contributing to cardiovascular complications. Hyperglycaemia-mediated neurohormonal activation increases arterial stiffness, and is an important contributing factor for hypertension. Since the sodium glucose cotransport-2 (SGLT2) inhibitor empagliflozin lowers blood pressure and $\mathrm{HbA} 1 \mathrm{c}$ in type 1 diabetes mellitus, we hypothesized that this agent would also reduce arterial stiffness and markers of sympathetic nervous system activity.

Methods: Blood pressure, arterial stiffness, heart rate variability (HRV) and circulating adrenergic mediators were measured during clamped euglycaemia (blood glucose 4-6 mmol/L) and hyperglycaemia (blood glucose 9-11 mmol/L) in 40 normotensive type 1 diabetes mellitus patients. Studies were repeated after 8 weeks of empagliflozin (25 mg once daily).
\end{abstract}

Results: In response to empagliflozin during clamped euglycaemia, systolic blood pressure $(111 \pm 9$ to $109 \pm 9$ $\mathrm{mmHg}, \mathrm{p}=0.02)$ and augmentation indices at the radial $(-52 \% \pm 16$ to $-57 \% \pm 17, \mathrm{p}=0.0001)$, carotid $(+1.3 \pm 1$ 7.0 to $-5.7 \pm 17.0 \%, p<0.0001)$ and aortic positions $(+0.1 \pm 13.4$ to $-6.2 \pm 14.3 \%, p<0.0001)$ declined. Similar effects on arterial stiffness were observed during clamped hyperglycaemia without changing blood pressure under this condition. Carotid-radial pulse wave velocity decreased significantly under both glycemic conditions ( $p \leq 0.0001)$, while declines in carotid-femoral pulse wave velocity were only significant during clamped hyperglycaemia $(5.7 \pm 1.1$ to $5.2 \pm 0.9 \mathrm{~m} / \mathrm{s}, \mathrm{p}=0.0017)$. HRV, plasma noradrenalin and adrenaline remained unchanged under both clamped euglycemic and hyperglycemic conditions.

Conclusions: Empagliflozin is associated with a decline in arterial stiffness in young type 1 diabetes mellitus subjects. The underlying mechanisms may relate to pleiotropic actions of SGLT2 inhibition, including glucose lowering, antihypertensive and weight reduction effects.

Trial registration: Clinical trial registration: NCT01392560

Keywords: Diabetes mellitus, Systemic blood pressure, SGLT2 inhibition, Empagliflozin, Hyperglycaemia, Arterial stiffness, Heart rate variability

\footnotetext{
* Correspondence: david.cherney@uhn.on.ca

'Division of Nephrology, University Health Network, University of Toronto, Toronto General Hospital, 585 University Ave, Toronto 8N-845, M5G 2N2, Ontario, Canada

Full list of author information is available at the end of the article
} waiver (http://creativecommons.org/publicdomain/zero/1.0/) applies to the data made available in this article, unless otherwise stated. 


\section{Background}

In type 2 diabetes mellitus (T2D), approximately $40 \%$ of patients are hypertensive at the time of diagnosis, and in type 1 DM (T1D), the prevalence of hypertension increases with longer duration of disease [1]. Hyperglycaemia plays a critical role in the pathogenesis of diabetic complications and in the development of hypertension in patients with DM. This is explained in part through effects on activation of the renin angiotensin aldosterone system (RAAS) and sympathetic nervous system (SNS) as well as suppression of nitric oxide [2], leading to macrovascular dysfunction including increased arterial stiffness [3]. Together with changes in arterial structure secondary to long-standing DM, hyperglycaemia-mediated neurohormonal activation increases vascular tone and arterial stiffness, thereby raising the risk of hypertension [4,5]. Unfortunately, blockade of RAAS pathways provides incomplete protection against the development of diabetic complications [6] and dual RAAS blockade strategies may increase the risk of serious adverse effects such as acute kidney injury and hyperkalemia $[7,8]$. The development of safe, new agents that augment vascular protection in patients with DM is therefore of the utmost importance.

Aside from effects of RAAS and SNS activation on vascular function, arterial stiffness increases under the influence of ambient hyperglycaemia and can be improved through tight glycemic control [9-11]. Intensification of glycemic control in both T1D and T2D reduces arterial stiffness, which may contribute to improved blood pressure control and a decreased risk of cardiovascular complications [12-14]. Unfortunately, intensive glucose lowering strategies also increase the risk of severe hypoglycemic events [15-17] and promote weight gain and sodium retention resulting in higher blood pressure [16-18], thereby mitigating the benefit that can be achieved through tight glycemic control [19].

Alternatively, glucose lowering may be achieved with novel sodium glucose co-transport 2 (SGLT2) inhibitors in patients with T2D [20,21]. Since these agents lower blood glucose through insulin-independent increases in urinary glucose excretion, SGLT2 inhibition has also been used in T1D patients, and improves glycemic control $[22,23]$. In addition to having a low risk of hypoglycaemia, this class of oral hypoglycemic agents induces clinically relevant and sustained weight loss and declines in blood pressure in patients with T1D [22,24] and T2D [20,25]. The blood pressure lowering effect of SGLT2 inhibition may be related to several mechanisms, including diuretic effects, changes in neurohormonal activation, improved glycemic control and decreases in body weight (Figure 1). Despite these pleiotropic effects, mechanistic human data related to antihypertensive effects of these agents remain limited. A thorough understanding of the blood pressure lowering effects of SGLT2 inhibition is important, since long-term cardiovascular outcome trials are underway, and human mechanistic data may help to interpret the results of these clinical trials.

In a trial designed with the primary objective of investigating renal hemodynamic effects of SGLT2 inhibition, we examined systemic hemodynamic effects of empagliflozin (Boehringer Ingelheim, Ingelheim, Germany), a new and highly selective SGLT2 inhibitor. We hypothesized that

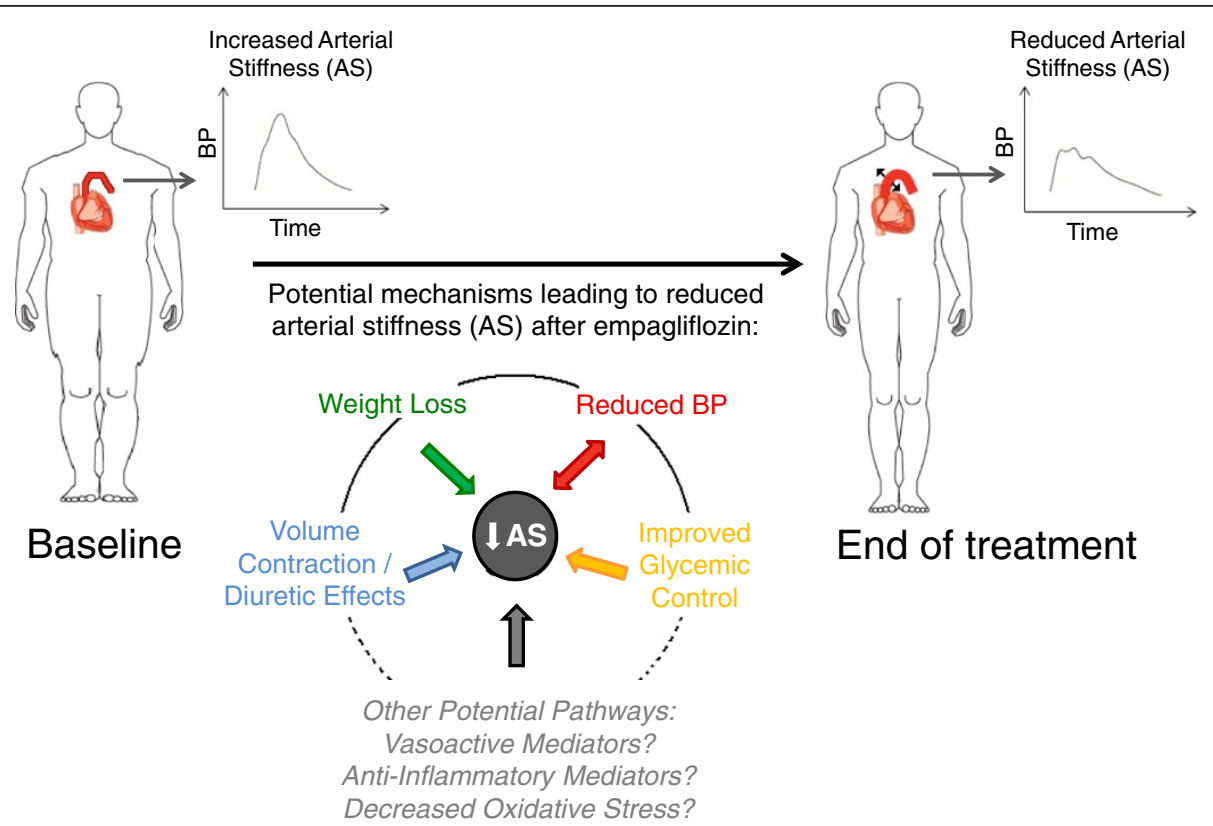

Figure 1 Physiological mechanisms implicated in arterial stiffness lowering effects with sodium glucose cotransport-2 inhibition. 
empagliflozin would decrease arterial stiffness, including augmentation index and pulse wave velocity, leading to declines in systemic blood pressure. In addition, due to the stimulatory effect of hyperglycaemia on the SNS [26], we hypothesized that empagliflozin would reduce neurohormonal activation, leading to improved heart rate variability (HRV) and a decline in plasma adrenaline and noradrenalin.

\section{Methods}

\section{Subjects}

In this 8-week, open-label, prospective clinical trial, 42 participants with T1D were treated with empagliflozin $25 \mathrm{mg}$ once daily (NCT01392560). Inclusion and exclusion criteria at screening have been described elsewhere [24] (http://www.clinicaltrials.gov/ct2/show/NCT01392560). In brief, men and women $\geq 18$ years with $\mathrm{T} 1 \mathrm{D} \geq 12$ months with estimated GFR $\geq 60 \mathrm{ml} / \mathrm{min} / 1.73 \mathrm{~m}^{2}$ and no hypertension or macroalbuminuria were included. Patients taking medication known to interfere with RAAS activity and/or renal function based on investigator judgment were excluded [24]. Of note, none of the patients were taking medications that can affect arterial stiffness or blood pressure, such as renin angiotensin aldosterone system blockers, beta blockers, calcium channel blockers, diuretics or other antihypertensive agents. Two cases of diabetic ketoacidosis leading to discontinuation occurred during the study: one in the context of insulin pump failure and the other in the setting of acute gastroenteritis. These patients were withdrawn within the first 3 days of drug exposure and were included only in the safety analyses. Detailed data regarding other adverse effects of empagliflozin in this cohort have been reported elsewhere [24]. 40 subjects completed the study (Table 1) and the primary endpoint of change in renal function in response to empagliflozin has been reported elsewhere [24]. In this manuscript we report the pre-specified exploratory vascular endpoint results. The

Table 1 Baseline Clinical Characteristics of the 40 Patients with Type 1 Diabetes

\begin{tabular}{lc}
\hline Male sex (\%) & $20(50 \%)$ \\
Age (yr - mean \pm SD) & $24.3 \pm 5.1$ \\
Diabetes Duration (yr) & $4(10)$ \\
$\quad>1-5$ years - $\mathrm{n}(\%)$ & $36(90)$ \\
$\quad>5$ years - $\mathrm{n}(\%)$ & $4(10)$ \\
Current Smoking - $\mathrm{n}(\%)$ & 0 \\
Presence of Non-Proliferative Retinopathy - $\mathrm{n}(\%)$ & $24.5 \pm 3.2$ \\
Body mass index (kg/m²) & $8.0 \pm 0.9$ \\
HbA1C (\%) & $1.2 \pm 0.9$ \\
Urine albumin/creatinine ratio (mg/mmol)
\end{tabular}

Urine albumin/creatinine ratio reported is the average of the baseline values that were collected during clamped euglycemia and hyperglycemia. Urinary albumin concentration was determined by immunoturbidimetry and $\mathrm{HbA} 1 \mathrm{C}$ was measured by high-performance liquid chromatography [27].
Research Ethics Board at the University Health Network (Toronto, Canada) approved the protocol and all subjects gave informed consent prior to start of study procedures. The study was conducted according to the International Conference on Harmonization on Good Clinical Practice.

\section{Experimental design}

Subjects adhered to a sodium-replete and moderate protein diet during the 7-day period before each experiment, as described previously [27]. After admission to the Renal Physiology Laboratory, euglycemic $(4-6 \mathrm{mmol} / \mathrm{L})$ conditions on the first day, followed by hyperglycemic $(9-11 \mathrm{mmol} / \mathrm{L})$ conditions on the second day, were maintained by a modified glucose clamp technique. Studies were performed on two consecutive days at baseline after maintenance of the clamp within the desired range for approximately 5 hours preceding and during all investigations, as described previously [24].

Following the glucose clamp, right radial artery and carotid waveforms were recorded with a high-fidelity micromanometer and using the validated transfer function, corresponding central aortic pressure waveform data were generated (SPC-301, Millar Instruments SphygmoCor, AtCor Medical Systems Inc., Sydney, Australia). Augmentation index, an estimate of systemic arterial stiffness was calculated as the difference between the second systolic peak and inflection point, expressed as a percentage of the central pulse pressure corrected to an average heart rate of 75 beats per minute. The aortic pulse wave velocity (PWV) was measured using the same device by sequentially recording ECG-gated right carotid and radial artery waveforms. Two vascular measurements were obtained for each parameter and the average value reported. The use of the SphygmoCor device to assess arterial stiffness parameters has been previously published by our group [28]. Automated blood pressure measurements were obtained using a DINAMAP machine (Critikon, Tampa, Florida) and the average of two values obtained immediately prior to the arterial stiffness assessments are reported.

After completion of arterial stiffness testing, HRV testing was performed using AtCor software (Atcor Medical Systems Inc., Sydney, Australia). In brief, two 10-minute segments were recorded. Vagal tone (Root Mean Square Successive Difference - RMSSD) and sympathetic activity (Standard Deviation of Normal-to-Normal interval SDNN) measures were obtained at each of the two periods and the results were then averaged. Plasma noradrenalin and adrenaline concentrations were obtained on each of the study days according to standard, previously described methods [29].

\section{Statistical analysis}

The primary endpoint of this study was change in GFR after treatment with empagliflozin for 8 weeks [24]. 
Sample size calculations were based on anticipated changes in GFR [24]. Accordingly, results reported in this manuscript were pre-specified, exploratory endpoints. Paired t-tests were performed to evaluate differences in vascular measurements and neurohormonal outcomes before and after treatment with empagliflozin. A repeated measures model was used to evaluate differences in response to empagliflozin between euglycemic and hyperglycemic conditions. All statistical analyses were performed using the statistical package SAS (Version 9.2).

\section{Results}

\section{Baseline demographic parameters}

The baseline characteristics of this T1D study cohort are described in Table 1. This cohort comprised a mainly young group of participants with uncomplicated T1D that has been described in more detail elsewhere [22,24]. All except for 4 patients (ages 31, 33, 34 and 44 years old) were between the ages of 18-30.

\section{Effects of empagliflozin on blood pressure, arterial stiffness and heart rate variability during clamped euglycaemia}

During clamped euglycaemia, empagliflozin significantly reduced systolic blood pressure, radial augmentation index, carotid augmentation index and aortic augmentation index (Table 2, Figure 2). Carotid-radial pulse wave velocity decreased significantly ( $\mathrm{p}=0.0001$ ), while similar trends for carotid-femoral pulse wave velocity were not significant. Effects on vagal tone (RMSSD) and SNS activity (SDNN, plasma noradrenalin and adrenaline) were not significant.
Effects of empagliflozin on blood pressure, arterial stiffness and heart rate variability during clamped hyperglycaemia

During clamped hyperglycemic conditions, treatment with empagliflozin did not reduce blood pressure significantly, despite significant effects on radial augmentation index, carotid augmentation index and aortic augmentation index (Table 2, Figure 2). Empagliflozin decreased both carotid-radial and carotid-femoral pulse wave velocity under clamped hyperglycemic conditions (Table 2). Similar to effects during clamped euglycemic conditions, effects on SNS function including RMSSD, SDNN, plasma noradrenalin and adrenaline, were not significant (Table 2, Figure 2). In the repeated measures model used to evaluate differences in response to empagliflozin between glycemic conditions, there were no significant differences in any of the hemodynamic parameters $(\mathrm{p}>0.05$, data not shown).

\section{Discussion}

Despite optimal medical therapy including RAAS inhibitors, many patients continue to develop hypertension, chronic kidney disease and cardiovascular diseases [6]. Moreover, in T1D, primary prevention strategies with RAAS blockers are ineffective [7]. Intensive glucose lowering therapies exert long lasting renal and cardiovascular protective effects, highlighting the need for improved glucose control in patients with T1D and T2D [30-32]. Due to their unique insulin-independent mechanism of action, SGLT2 inhibitors lower blood pressure and improve glycemic control, while at the same time avoiding potential risks of increased insulin doses such as hypoglycaemia,

Table 2 Hemodynamic responses to empagliflozin in patients with type 1 diabetes during clamped euglycemia and hyperglycemia (mean \pm SD)

\begin{tabular}{|c|c|c|c|c|c|c|}
\hline & \multicolumn{3}{|c|}{ Euglycemia } & \multicolumn{3}{|c|}{ Hyperglycemia } \\
\hline & Baseline & Empagliflozin & p-value & Baseline & Empagliflozin & p-value \\
\hline \multicolumn{7}{|l|}{ Blood pressure } \\
\hline Systolic blood pressure $(\mathrm{mmHg})$ & $111.2 \pm 8.9$ & $108.5 \pm 8.7$ & 0.02 & $112.1 \pm 9.8$ & $110.6 \pm 9.8$ & 0.2797 \\
\hline Diastolic blood pressure (mmHg) & $63.6 \pm 8.5$ & $63.1 \pm 8.1$ & 0.6191 & $65.2 \pm 8.3$ & $63.8 \pm 7.3$ & 0.2497 \\
\hline Pulse (beats per minute) & $74.2 \pm 13.1$ & $71.8 \pm 13.8$ & 0.1885 & $72.0 \pm 11.0$ & $70.8 \pm 12.8$ & 0.4919 \\
\hline \multicolumn{7}{|l|}{ Vascular parameters } \\
\hline Radial augmentation index (\%) & $-52.0 \pm 16.1$ & $-57.0 \pm 16.7$ & 0.0001 & $-47.9 \pm 17.3$ & $-52.1 \pm 17.6$ & 0.0190 \\
\hline Carotid radial pulse wave velocity $(\mathrm{m} / \mathrm{s})$ & $7.3 \pm 1.1$ & $6.7 \pm 0.9$ & 0.0001 & $7.9 \pm 1.1$ & $6.9 \pm 0.9$ & $<0.0001$ \\
\hline Carotid femoral pulse wave velocity $(\mathrm{m} / \mathrm{s})$ & $5.5 \pm 0.9$ & $5.3 \pm 1.0$ & 0.1366 & $5.7 \pm 1.1$ & $5.2 \pm 0.9$ & 0.0017 \\
\hline \multicolumn{7}{|l|}{ Heart rate variability } \\
\hline RMSSD (milliseconds) & $46.3 \pm 22.9$ & $53.6 \pm 32.1$ & 0.1050 & $58.0 \pm 35.1$ & $63.3 \pm 37.7$ & 0.3004 \\
\hline SDNN (milliseconds) & $69.3 \pm 24.0$ & $73.8 \pm 33.2$ & 0.3278 & $77.7 \pm 32.8$ & $83.4 \pm 32.2$ & 0.2837 \\
\hline \multicolumn{7}{|l|}{ Biochemistry } \\
\hline Plasma adrenaline (nmol/L) & $0.13 \pm 0.07$ & $0.12 \pm 0.06$ & 0.2946 & $0.13 \pm 0.09$ & $0.12 \pm 0.06$ & 0.1097 \\
\hline Plasma nordrenaline (nmol/L) & $0.75 \pm 0.35$ & $0.76 \pm 0.36$ & 0.8985 & $0.77 \pm 0.95$ & $0.70 \pm 0.35$ & 0.6230 \\
\hline
\end{tabular}




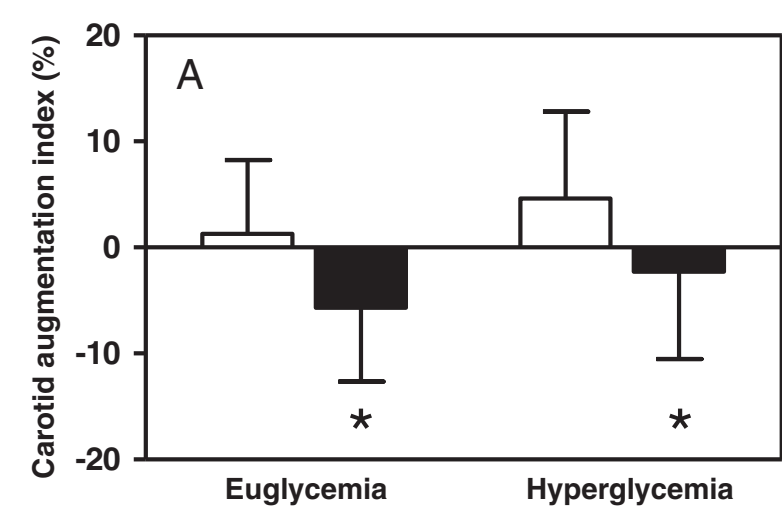

\section{$\square$ Baseline \\ EMPA}

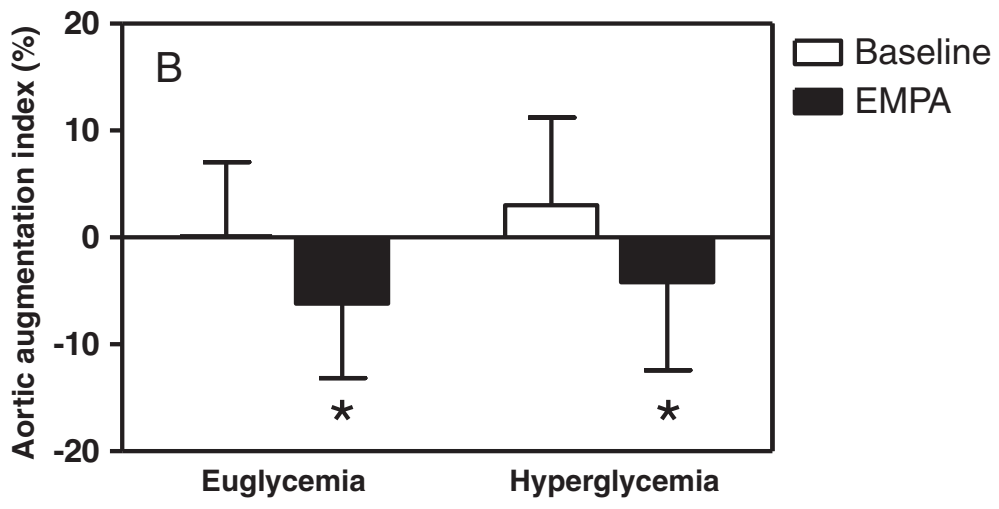

Figure 2 The effect of empagliflozin on carotid (A) and aortic (B) augmentation indices during clamped euglycaemia and hyperglycaemia in patients with type 1 diabetes. ${ }^{*} p<0.0001$ compared to baseline parameter under the same glycemic condition.

hypertension and weight gain [33]. These agents are also generally safe and well tolerated [22,34-39]. Our goal was to further clarify the mechanistic basis for the blood pressure lowering effect of empagliflozin, including effects on arterial stiffness and neurohormonal activation measured by heart rate variability, since both of these parameters are associated with systemic blood pressure and correlate with long-term renal and cardiovascular outcomes [5,40-42]. Our major novel finding was that empagliflozin reduced measures of arterial stiffness under both clamped euglycemic and hyperglycemic conditions. We also observed that after treatment with empagliflozin for 8 weeks, systolic blood pressure decreased significantly in normotensive patients with T1D.

\section{The effect of oral hypoglycemic agents on arterial stiffness}

Previous studies in T2D have suggested that oral hypoglycemic agents such as metformin reduce blood pressure, primarily through improving glycemic control [12-14,43]. In contrast, other oral hypoglycemic agents such as sulfonylureas that increase the risk of severe hypoglycemic events and lead to body weight gain may promote the development of hypertension [44]. Perhaps as a result of increasing weight, these traditional oral hypoglycemic agents do not improve arterial stiffness parameters and a significant proportion of patients develop hypertension with increasing diabetes duration $[45,46]$. Since existing oral agents are not approved nor appropriate in T1D, the options for improving glycemic control in patients with T1D are limited to intensifying insulin regimens, which can have the same adverse effects on weight, hypoglycemic risk and blood pressure as in T2D patients [30-32]. This study shows for the first time that an oral hypoglycemic agent that improves glycemic control over an 8-week period in patients with T1D can also reduce arterial stiffness, which may in part be responsible for the antihypertensive effects associated with SGLT2 inhibition.

\section{Regulators of arterial stiffness}

Arterial stiffness is influenced by a variety of factors, including neurohormonal mediators and changes in arterial structure [4]. We have previously demonstrated in this cohort that empagliflozin induces a modest increase in plasma RAAS mediators, including aldosterone and angiotensin II, which is likely a compensatory response to effective circulating volume contraction, similar to 
expected effects of a thiazide diuretic [24,47]. The mild increase in plasma RAAS levels with empagliflozin was insufficient to counteract the effect of effective circulating volume contraction, resulting in decreases in blood pressure and arterial stiffness. A similar observation was made for vasodilatory $\mathrm{NO}$, for which we observed a decline in plasma levels in our previous work, which was also unlikely to have accounted for decreases in blood pressure or arterial stiffness in this cohort [24]. We therefore concluded that the beneficial hemodynamic changes observed with empagliflozin were unlikely to be influenced by concomitant changes in systemic RAAS and NO activity. Consequently we hypothesized that improved arterial compliance after empagliflozin could be related to changes in autonomic nervous system function, reflected by increased HRV and lower circulating levels of adrenaline and noradrenalin. However, empagliflozin did not affect HRV or plasma adrenergic system markers, suggesting that the mechanisms responsible for blood pressure and arterial stiffness lowering are independent of effects on autonomic nervous system activity. Nevertheless, our results do not exclude the possibility that other neurohormonal factors related to hyperglycaemia may have contributed to changes in blood pressure and arterial stiffness, such as decreased reactive oxygen species generation [48].

While neither RAAS, NO nor SNS activity can explain our results, we postulate that changes in arterial stiffness with empagliflozin are due to several other factors (Figure 1). First, weight loss independently decreases blood pressure and arterial stiffness [49]. Empagliflozin was associated with a significant reduction in weight of $2.7 \mathrm{~kg}$ in our cohort and this may have contributed to benefits on blood pressure and arterial stiffness, as previously reported $[22,24]$. This weight loss was likely in part due to loss of fat, since waist circumference declined. Second, decreases in daily insulin doses have been correlated with improved arterial compliance in T2D, and a similar interaction may have occurred in our T1D cohort since total daily insulin doses decreased significantly by the end of treatment $[22,50]$. Third, other diuretic agents such as thiazides lower arterial stiffness and these effects are likely in part due to direct effects on vascular smooth muscle relaxation after induction of a negative sodium balance $[51,52]$. Similar diuretic effects with SGLT2 inhibition may have contributed to the decline in arterial stiffness in our cohort. Next, empagliflozin-induced weight loss and improved glycemic control may exert antiinflammatory changes, which favour improvements in blood pressure and arterial stiffness [49]. For example, in experimental models of diabetes, SGLT2 inhibition reduces oxidative stress and suppresses markers of inflammation and fibrosis, including nuclear factor $\kappa \beta$ and collagen IV expression [53,54]. Due to the strong relationship between inflammation, cardiovascular complications and renal disease, future studies should clarify the ability of SGLT2 inhibitors to suppress inflammation in humans [55].

\section{Arterial stiffness and long term clinical outcomes}

Due to their insulin-independent mechanism of action and as shown in animal models [56], SGLT2 inhibitors have the potential to be used in T1D [22] in addition to T2D [33]. Furthermore, SGLT2 inhibition may avoid some of the most common treatment-related side effects in T2D that have limited the benefits of traditional oral hypoglycemic agents, including significant weight gain, development and worsening of hypertension and severe hypoglycemic events $[33,39,57]$. Our observations are, to our knowledge, the first to suggest possible functional benefits of an oral hypoglycemic agent on large vessel function in T1D patients. The improvement in arterial compliance is important because previous studies have demonstrated strong, independent associations between macrovascular complications and arterial stiffness in T2D [58,59]. Increased arterial stiffness is also independently associated with clinically relevant outcomes in T1D patients, including cardiovascular, renal, retinal and autonomic complications [42]. Importantly, the beneficial effects of conventional cardiovascular protective agents such as ACE inhibitors have been in part attributed to improvements in arterial compliance [60]. Ultimately, large ongoing clinical outcomes trials in T2D will determine if changes in arterial stiffness or blood pressure with SGLT2 inhibition translate into long-term renal or cardiovascular protection.

This trial has some limitations. First, the duration of therapy was limited to 8 weeks. Therefore, conclusions regarding longer term clinical benefits cannot be made from this study. Second, further work is needed to explore the interdependence among beneficial effects on arterial stiffness, including weight loss, glycemic control and blood pressure seen with empagliflozin. In particular, we could not determine if changes in blood pressure were based on declines in arterial stiffness, or whether reduced arterial stiffness was responsible for the fall in systolic blood pressure. Nevertheless, consistent changes in these vascular parameters are encouraging and support the rationale for ongoing long-term cardiovascular outcome trials. Third, these results in young patients with uncomplicated T1D cannot be generalized to older T1D patients, T1D patients with hypertension or to those with T2D. Given the important relationship between age and arterial stiffness, future work should determine if SGLT2 inhibition exerts similar effects in older individuals. Finally, measures of arterial stiffness have a high variability. As a consequence, our results should be viewed as exploratory and should be confirmed in future studies. 


\section{Conclusions}

In summary, empagliflozin reduces arterial stiffness in patients with T1D. Longer-term studies are warranted to assess the safety and clinical effects of these agents in T1D. Moreover, since arterial stiffness is a surrogate marker for renal and cardiovascular clinical outcomes, future trials should assess the effect of empagliflozin on cardiorenal protection in patients with diabetes.

\section{Competing interests}

The results presented in this paper have not been published previously in whole or in part. Some of the results presented in this paper were presented at the American Society of Nephrology Kidney Week in November 2013. D.Z. I.C. has received speaker honoraria from Boehringer Ingelheim and B.A.P received operational funding with D.Z.I.C. for this work. N.S., N.F., H.J.W. O.E.J., U.C.B., M.V E. are employees of Boehringer Ingelheim.

\section{Authors' contributions}

DZIC, BAP, RH, researched data, wrote the manuscript. NF, HJW, NS, OEJ, UCB, MvE contributed to discussion, reviewed/edited manuscript. All authors have approved the final version of this manuscript.

\section{Authors' information}

David ZI Cherney, Bruce A Perkins and Nima Soleymanlou are co-primary first authors and Maximilian von Eynatten and Uli C Broedl contributed equally as co-senior authors.

\section{Acknowledgements}

This work was supported by Boehringer Ingelheim (to D.Z.I.C. and B.A.P.) D.Z. I.C. was also supported by a Kidney Foundation of Canada Scholarship and a Canadian Diabetes Association-KRESCENT Program Joint New Investigator Award and receives operating support from the Heart and Stroke Foundation of Canada. The authors would also like to thank Dr. Paul Yip and Jenny Cheung for their invaluable assistance with biochemical assays included in this work. Finally, the authors are grateful to the study participants whose time and effort are critical to the success of our research program.

\section{Author details}

'Division of Nephrology, University Health Network, University of Toronto, Toronto General Hospital, 585 University Ave, Toronto 8N-845, M5G 2N2, Ontario, Canada. ${ }^{2}$ Division of Endocrinology, University Health Network, University of Toronto, Toronto, Canada. ${ }^{3}$ Boehringer Ingelheim Canada Ltd./ Ltée, Burlington, Canada. ${ }^{4}$ Boehringer Ingelheim Pharmaceuticals, Inc., Ridgefield, CT, USA. ${ }^{5}$ Boehringer Ingelheim Pharma GmbH \& Co.KG, Ingelheim, Germany.

Received: 18 November 2013 Accepted: 23 January 2014 Published: 29 January 2014

\section{References}

1. Hypertension in Diabetes Study (HDS): I. Prevalence of hypertension in newly presenting type 2 diabetic patients and the association with risk factors for cardiovascular and diabetic complications.J Hypertens 1993, 11:309-317.

2. Bellien J, Favre J, lacob M, Gao J, Thuillez C, Richard V, Joannides R: Arterial stiffness is regulated by nitric oxide and endothelium-derived hyperpolarizing factor during changes in blood flow in humans. Hypertension 2010, 55:674-680.

3. Sasson AN, Cherney DZ: Renal hyperfiltration related to diabetes mellitus and obesity in human disease. World J Diabetes 2012, 3:1-6.

4. Wilkinson IB, McEniery CM: Arterial stiffness, endothelial function and novel pharmacological approaches. Clin Exp Pharmacol Physiol 2004, 31:795-799.

5. van Ittersum FJ, Schram MT, van der Heijden-Spek JJ, Van Bortel LM, Elte JW, Biemond P, Staessen JA, Donker AJ, Stehouwer CD: Autonomic nervous function, arterial stiffness and blood pressure in patients with Type I diabetes mellitus and normal urinary albumin excretion. I Hum Hypertens 2004, 18:761-768.
6. Ficociello LH, Perkins BA, Silva KH, Finkelstein DM, Ignatowska-Switalska $\mathrm{H}$, Gaciong Z, Cupples LA, Aschengrau A, Warram JH, Krolewski AS: Determinants of progression from microalbuminuria to proteinuria in patients who have type 1 diabetes and are treated with angiotensin-converting enzyme inhibitors. Clin J Am Soc Nephrol 2007, 2:461-469.

7. Mauer M, Zinman B, Gardiner R, Suissa S, Sinaiko A, Strand T, Drummond K, Donnelly S, Goodyer P, Gubler MC, et al: Renal and retinal effects of enalapril and losartan in type 1 diabetes. N Engl J Med 2009, 361:40-51.

8. Mann JF, Schmieder RE, McQueen M, Dyal L, Schumacher H, Pogue J, Wang X, Maggioni A, Budaj A, Chaithiraphan S, et al: Renal outcomes with telmisartan, ramipril, or both, in people at high vascular risk (the ONTARGET study): a multicentre, randomised, double-blind, controlled trial. Lancet 2008, 372:547-553.

9. Gordin D, Ronnback M, Forsblom C, Makinen V, Saraheimo M, Groop PH: Glucose variability, blood pressure and arterial stiffness in type 1 diabetes. Diabetes Res Clin Pract 2008, 80:e4-e7.

10. Gordin D, Ronnback M, Forsblom C, Heikkila O, Saraheimo M, Groop PH: Acute hyperglycaemia rapidly increases arterial stiffness in young patients with type 1 diabetes. Diabetologia 2007, 50:1808-1814.

11. Manolis AJ, Iraklianou S, Pittaras A, Zaris M, Tsioufis K, Psaltiras G, Psomali D, Foussas S, Gavras I, Gavras H: Arterial compliance changes in diabetic normotensive patients after angiotensin-converting enzyme inhibition therapy. Am J Hypertens 2005, 18:18-22.

12. Kim SG, Ryu OH, Kim HY, Lee KW, Seo JA, Kim NH, Choi KM, Lee J, Baik SH, Choi DS: Effect of rosiglitazone on plasma adiponectin levels and arterial stiffness in subjects with prediabetes or non-diabetic metabolic syndrome. Eur J Endocrinol 2006, 154:433-440.

13. Agarwal N, Rice SP, Bolusani H, Luzio SD, Dunseath G, Ludgate M, Rees DA: Metformin reduces arterial stiffness and improves endothelial function in young women with polycystic ovary syndrome: a randomized, placebocontrolled, crossover trial. J Clin Endocrinol Metab 2010, 95:722-730.

14. Kiyici S, Ersoy C, Kaderli A, Fazlioglu M, Budak F, Duran C, Gul OO, Sigirli D, Baran I, Tuncel E, et al: Effect of rosiglitazone, metformin and medical nutrition treatment on arterial stiffness, serum MMP-9 and MCP-1 levels in drug naive type 2 diabetic patients. Diabetes Res Clin Pract 2009, 86:44-50.

15. Adler Al, Stratton IM, Neil HA, Yudkin JS, Matthews DR, Cull CA, Wright AD, Turner RC, Holman RR: Association of systolic blood pressure with macrovascular and microvascular complications of type 2 diabetes (UKPDS 36): prospective observational study. BMJ 2000, 321:412-419.

16. Macisaac RJ, Jerums G: Intensive glucose control and cardiovascular outcomes in type 2 diabetes. Heart Lung Circ 2011, 20:647-654.

17. The Diabetes Control and Complications (DCCT) Research Group: Effect of intensive therapy on the development and progression of diabetic nephropathy in the Diabetes Control and Complications Trial. Kidney Int 1995, 47:1703-1720.

18. The Diabetes Control and Complications Trial Research Group: The effect of intensive treatment of diabetes on the development and progression of long-term complications in insulin-dependent diabetes mellitus. N Engl J Med 1993, 329:977-986.

19. Zoungas S, Patel A, Chalmers J, de Galan BE, Li Q, Billot L, Woodward M, Ninomiya T, Neal B, MacMahon S, et al: Severe hypoglycemia and risks of vascular events and death. N Engl J Med 2010, 363:1410-1418.

20. List JF, Whaley JM: Glucose dynamics and mechanistic implications of SGLT2 inhibitors in animals and humans. Kidney Int Suppl 2011, 120:S20-\$27.

21. Rosenstock J, Jelaska A, Wang F, Kim G, Broedl UC, Woerle HJ: Empagliflozin as add-on to basal insulin for 78 weeks improves glycemic control with weight loss in insulin-treated type 2 diabetes (T2DM). Diabetes 2013, 62:A285 [1102-P].

22. Perkins BA, Cherney DZI, Partridge H, Soleymanlou N, Tschirhart H, Zinman B, Fagan N, Kaspers S, Woerle HJ, Broedl UC, et al: The sodium glucose co-transporter-2 (SGLT2) inhibitor empagliflozin improves glycemic control in patients with type 1 diabetes: a single-arm clinical trial. Diabetes Care 2013. in press.

23. Mudaliar S, Armstrong DA, Mavian AA, O'Connor-Semmes R, Mydlow PK, Ye J, Hussey EK, Nunez DJ, Henry RR, Dobbins RL: Remogliflozin etabonate, a selective inhibitor of the sodium-glucose transporter 2, improves serum glucose profiles in type 1 diabetes. Diabetes Care 2012, 35:2198-2200.

24. Cherney DZI, Perkins BA, Soleymanlou N, Maione M, Lai V, Lee A, Fagan NM, Woerle HJ, Johansen OE, Broedl UC, et al: The Renal Hemodynamic Effect 
of SGLT2 Inhibition in Patients with Type 1 Diabetes. Circulation 2013. In press.

25. List JF, Woo V, Morales E, Tang W, Fiedorek FT: Sodium-glucose cotransport inhibition with dapagliflozin in type 2 diabetes. Diabetes Care 2009, 32:650-657.

26. Villafana S, Huang F, Hong E: Role of the sympathetic and renin angiotensin systems in the glucose-induced increase of blood pressure in rats. Eur J Pharmacol 2004, 506:143-150.

27. Cherney DZ, Scholey JW, Nasrallah R, Dekker MG, Slorach C, Bradley TJ, Hebert RL, Sochett EB, Miller JA: Renal hemodynamic effect of cyclooxygenase 2 inhibition in young men and women with uncomplicated type 1 diabetes mellitus. Am J Physiol Renal Physiol 2008, 294:F1336-F1341.

28. Cherney DZ, Scholey JW, Jiang S, Har R, Lai V, Sochett EB, Reich HN: The effect of direct renin inhibition alone and in combination with ACE inhibition on endothelial function, arterial stiffness, and renal function in type 1 diabetes. Diabetes Care 2012, 35:2324-2330.

29. Cherney DZ, Lai V, Miller JA, Scholey JW, Reich HN: The angiotensin II receptor type 2 polymorphism influences haemodynamic function and circulating RAS mediators in normotensive humans. Nephrol Dial Transplant 2010, 25:4093-4096.

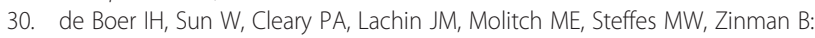
Intensive diabetes therapy and glomerular filtration rate in type 1 diabetes. N Engl J Med 2011, 365:2366-2376.

31. Weiss IA, Valiquette G, Schwarcz MD: Impact of glycemic treatment choices on cardiovascular complications in type 2 diabetes. Cardiol Rev 2009, 17:165-175.

32. Bilous R: Microvascular disease: what does the UKPDS tell us about diabetic nephropathy? Diabet Med 2008, 25(Suppl 2):25-29.

33. Ghosh RK, Ghosh SM, Chawla S, Jasdanwala SA: SGLT2 Inhibitors: a New emerging therapeutic class in the treatment of type 2 diabetes mellitus. J Clin Pharmacol 2012, 52:457-463.

34. Ring A, Brand T, Macha S, Breithaupt-Groegler K, Simons G, Walter B, Woerle $H J$, Broedl UC: The sodium glucose cotransporter 2 inhibitor empagliflozin does not prolong QT interval in a thorough QT (TQT) study. Cardiovasc Diabeto/ 2013, 12:70.

35. Kovacs CS, Seshiah V, Swallow R, Jones R, Rattunde H, Woerle HJ, Broedl UC: Empagliflozin improves glycaemic and weight control as add-on therapy to pioglitazone or pioglitazone plus metformin in patients with type 2 diabetes: a 24-week, randomized, placebo-controlled trial. Diabetes Obes Metab 2014, 16:147-158.

36. Haring HU, Merker L, Seewaldt-Becker E, Weimer M, Meinicke T, Woerle HJ, Broedl UC: Empagliflozin as add-on to metformin plus sulfonylurea in patients with type 2 diabetes: a 24-week, randomized, double-blind, placebo-controlled trial. Diabetes Care 2013, 36:3396-3404

37. Barnett AH, Mithal A, Manassie J, Jones R, Rattunde H, Woerle HJ, Broedl UC: Efficacy and safety of empagliflozin added to existing anti-diabetes therapy in patients with type 2 diabetes and chronic kidney disease: a randomised double-blind, placebo-controlled trial. Lancet Diabetes Endocrinol 2014. epub Jan 24

38. Roden M, Weng J, Eilbracht J, Delafont B, Kim G, Woerle H, Broedl UC Empagliflozin monotherapy with sitagliptin as an active comparator in patients with type 2 diabetes: a randomised, double-blind, placebocontrolled, phase 3 trial. Lancet Diabetes Endocrinol 2013, 1:208-219.

39. Jabbour SA: SGLT2 inhibitors to control glycemia in in type 2 diabetes mellitus: a new approach to an old problem. Postgrad Med 2014, 126:111-117.

40. Nurnberger J, Keflioglu-Scheiber A, Opazo Saez AM, Wenzel RR, Philipp T, Schafers RF: Augmentation index is associated with cardiovascular risk. J Hypertens 2002, 20:2407-2414.

41. Hermans MM, Henry R, Dekker JM, Kooman JP, Kostense PJ, Nijpels G, Heine RJ, Stehouwer CD: Estimated glomerular filtration rate and urinary albumin excretion are independently associated with greater arterial stiffness: the Hoorn Study. J Am Soc Nephrol 2007, 18:1942-1952.

42. Theilade S, Lajer M, Persson F, Joergensen C, Rossing P: Arterial stiffness is associated with cardiovascular, renal, retinal, and autonomic disease in type 1 diabetes. Diabetes Care 2013, 36:715-721.

43. Musso G, Gambino R, Cassader M, Pagano G: A novel approach to control hyperglycemia in type 2 diabetes: sodium glucose co-transport (SGLT) inhibitors: systematic review and meta-analysis of randomized trials. Ann Med 2012, 44:375-393.
44. Skyler JS, Bergenstal R, Bonow RO, Buse J, Deedwania P, Gale EA, Howard BV, Kirkman MS, Kosiborod M, Reaven P, et al: Intensive glycemic control and the prevention of cardiovascular events: implications of the ACCORD, ADVANCE, and VA diabetes trials: a position statement of the American Diabetes Association and a scientific statement of the American College of Cardiology Foundation and the American Heart Association. Circulation 2009, 119:351-357.

45. Forst T, Michelson G, Ratter F, Weber MM, Anders S, Mitry M, Wilhelm B, Pfutzner A: Addition of liraglutide in patients with Type 2 diabetes well controlled on metformin monotherapy improves several markers of vascular function. Diabet Med 2012, 29:1115-1118.

46. Koren S, Shemesh-Bar L, Tirosh A, Peleg RK, Berman S, Hamad RA, Vinker S, Golik A, Efrati S: The effect of sitagliptin versus glibenclamide on arterial stiffness, blood pressure, lipids, and inflammation in type 2 diabetes mellitus patients. Diabetes Technol Ther 2012, 14:561-567.

47. Koenig W, Binner L, Gabrielsen F, Sund M, Rosenthal J, Hombach V: Catecholamines and the renin-angiotensin-aldosterone system during treatment with felodipine ER or hydrochlorothiazide in essential hypertension. J Cardiovasc Pharmacol 1991, 18:349-353.

48. Shestakova MV, Jarek-Martynowa IR, Ivanishina NS, Kuharenko SS, Yadrihinskaya MN, Aleksandrov AA, Dedov II: Role of endothelial dysfunction in the development of cardiorenal syndrome in patients with type 1 diabetes mellitus. Diabetes Res Clin Pract 2005, 68(1):S65-S72.

49. Cooper JN, Buchanich JM, Youk A, Brooks MM, Barinas-Mitchell E, Conroy $M B$, Sutton-Tyrrell K: Reductions in arterial stiffness with weight loss in overweight and obese young adults: potential mechanisms. Atherosclerosis 2012, 223:485-490.

50. Hughes TM, Althouse AD, Niemczyk NA, Hawkins MS, Kuipers AL, SuttonTyrrell K: Effects of weight loss and insulin reduction on arterial stiffness in the SAVE trial. Cardiovasc Diabetol 2012, 11:114

51. Galan L, Ferrer T, Artiles A, Talavera K, Salinas E, Orta G, Garcia-Barreto D, Alvarez JL: Cardiac cellular actions of hydrochlorothiazide. Fundam Clin Pharmacol 2001, 15:9-17.

52. Mackenzie IS, McEniery CM, Dhakam Z, Brown MJ, Cockcroft JR, Wilkinson IB: Comparison of the effects of antihypertensive agents on central blood pressure and arterial stiffness in isolated systolic hypertension. Hypertension 2009, 54:409-413.

53. Panchapakesan U, Pegg K, Gross S, Komala MG, Mudaliar H, Forbes J, Pollock C, Mather A: Effects of SGLT2 inhibition in human kidney proximal tubular cells-renoprotection in diabetic nephropathy? PLOS One 2013, 8:e54442.

54. Osorio H, Coronel I, Arellano A, Pacheco U, Bautista R, Franco M, Escalante B. Sodium-glucose cotransporter inhibition prevents oxidative stress in the kidney of diabetic rats. Oxid Med Cell Longev 2012, 2012:542042.

55. Matheson A, Willcox MD, Flanagan J, Walsh BJ: Urinary biomarkers involved in type 2 diabetes: a review. Diabetes Metab Res Rev 2010, 26:150-171.

56. Luippold G, Klein T, Mark M, Grempler R: Empagliflozin, a novel potent and selective SGLT-2 inhibitor, improves glycaemic control alone and in combination with insulin in streptozotocin-induced diabetic rats, a model of type 1 diabetes mellitus. Diabetes Obes Metab 2012, 14:601-607.

57. Dluhy RG, MCMahon GT: Intensive glycemic control in the ACCORD and ADVANCE trials. N Engl J Med 2008, 358:2630-2633.

58. Mansour AS, Yannoutsos A, Majahalme N, Agnoletti D, Safar ME, Ouerdane S, Blacher J: Aortic stiffness and cardiovascular risk in type 2 diabetes. J Hypertens 2013, 31:1584-1592.

59. Cardoso CR, Ferreira MT, Leite NC, Salles GF: Prognostic Impact of Aortic Stiffness in High-Risk Type 2 Diabetic Patients: The Rio de Janeiro Type 2 Diabetes Cohort Study. Diabetes Care 2013.

60. Frishman $\mathrm{WH}$ : Increased vascular compliance/decreased cardiovascular risk: what the studies tell us. Heart Dis 2000, 2:384-388.

\section{doi:10.1186/1475-2840-13-28}

Cite this article as: Cherney et al:: The effect of empagliflozin on arterial stiffness and heart rate variability in subjects with uncomplicated type 1 diabetes mellitus. Cardiovascular Diabetology 2014 13:28. 